\title{
Job Focus: Revisiting Students' Communicative Needs and Industrial Demands
}

\author{
Jabbar Al Muzzamil Fareen \\ Sohar University
}

\begin{abstract}
Correspondence concerning this article should be addressed to Jabbar Al Muzzamil Fareen, Sohar University, P.O Box 44, Al Jameah Street, Sohar 311, Oman. E-mail: jamfareen2006@yahoo.com
\end{abstract}

\begin{abstract}
In an attempt to develop students' employability skills through a job-specific, needs based English for Specific Purposes (ESP) course, this paper investigated conducting a needs analysis to understand the perceptions of the final-year technical students, alumni, and Human Resources (HR) managers for promoting placements in the campus recruitments. By employing a qualitative ethnographic approach, an open-ended questionnaire was conducted with finalyear information technology students and structured and unstructured interviews with the HR managers and the alumni respectively. In this study, the communicative needs of the finalyear technical students were specifically addressed to provide them with career education and placement training and raise employment opportunities in their course of study. Based on the results of the questionnaire-based survey and subsequent observations in the structured and unstructured interviews, it is widely examined that all of the HR managers reflected on the importance of English language in corporate communications. The findings of the survey also reflected that the perceptions of the alumni and the expectations of the HR managers on verbal and nonverbal skills were well received by the final-year technical students. This is a positive development on the part of students as they were found to be thoroughly aware of their workplace needs and were keen to develop language, communication, and soft skills for successfully entering into the job market. This research implies that connecting institution and industry is a significant factor in helping students obtain job offers and develop the job-specific skills that meet the requirements of the industry.
\end{abstract}

Keywords: employability skills, learning outcomes, needs analysis, placement, syllabus design, job-specific learning

Engineering and technical students are on the urge of getting placements in Multinational Corporations (MNCs) and Information Technology Enabling Service (ITES) companies. The major aim and scope of this study was to analyze the language and communication skills of the technical students that are needed to get placements in the IT industry. A needs based questionnaire was carried out to analyze the jobspecific needs of their present and target situations. As English is widely used in global business contexts, oral and written English communication skills are vital for executing their jobs (Rogerson-Revell, 2007; Kassim \& Ali, 2010; Spence \& Liu, 2013). This is specifically reflected through the campus recruitment drives conducted in the professional and technical colleges of Tamil Nadu, India.

Analyzing needs in terms of students' present and target situations is inevitable for designing an ESP course today (Hutchinson \& Waters, 1987; West, 1994). Students need to have considerable awareness and desire to get placements during oncampus recruitments. It is necessary for them to prepare themselves for facing the recruitment board and getting job offer letters while they study. It is crucial for them to display their cognitive abilities, communication skills, and technical expertise and develop relevant employability skills to sustain their jobs in any workplace (Pavlin \& Svetlik, 2014). In the final year of the course, technical students need to get placements in campus interviews as the reputation of the students and the institution always revolves around their achievements in the academic programmes and the placement they obtain in reputed first-tier Multinational Corporations (MNCs). This has been the concern of students, teachers, syllabus designers, and institutional authorities as they expect the final-year technical students to get job offers in their course of study. The employers are also found to be anxious to hire capable students and specifically they expect the students to be competent and employable (Rhoder \& 
French, 1994; Ehrich et al., 2010; Lester, 2014). This research focuses on understanding the reflections of the technical students, alumni, and HR managers regarding the development of skills relevant for employment.

\section{Review of the Literature}

The present study aimed to conduct a job-specific needs analysis to identify the skills required to get job offers during on-campus recruitments. Needs analysis is an investigation tool to systematically analyze the needs of the learners and their learning needs to competently perform in a target communicative situation (Berwick, 1989). As Nunan (1996, p. 13) observes, "Techniques and procedures for collecting information to be used in syllabus design are referred to as needs analysis. These techniques have been borrowed and adopted from other areas of training and development, particularly those associated with industry and technology". Needs analysis will help language experts design the language course according to the perceived needs and demands of both academics and industry (Long, 2005). While discussing the significance of needs analysis in designing and developing an ESP course, Chaudhury (2009) emphasizes the importance of conducting a formal needs analysis and evaluation of the tertiary level communication course to meet the demands of the workplace.

The use of English language in the present educational and professional context is indispensable. English is globally recognized as the formal language in which job interviews are conducted. Communicating efficiently in English has become the basic requirement for a job and hence it is directly associated with the career prospects of any professional. While investigating the needs of the learners, Kayi (2008) found that the educational, survival, and job requirements are the major factors for learning English. Crosling and Ward (2002) found that communication skills and prominently oral skills are very important to prepare the students for placement. Belcher (2006) exemplifies the use of faceto-face communication, oral presentations, classroom presentations, discussions, and oral reports. These interpersonal communicational activities help to develop discursive empowerment among students to develop strategic skills in oral communication. As prospective employers are found to be dissatisfied with the written performance in writing emails and reports, Davies and Birbili (2000) explored that the employees are not sufficiently trained to develop their writing skills in their studies. In a research study conducted at Massey University, Gray et al. (2005, p. 432) found "the ability to express ideas clearly in writing" is the first- ranked choice of employers and the students consider "the ability to present information accurately" as the top priority for developing written communication. The employers considered clarity, accuracy, and brevity as the significant features of effective writing. Although employers consider 'report writing' as the required genre to develop business writing skills, they equally emphasize clarity, accuracy, and brevity in their writing.

It is generally accepted that both native and non-native English-speaking students are really unprepared and unfit to commit to their services. Tucker (2011, p. 116) reflected on the unpreparedness of the US students in schools, saying, "The Common Core State Standards are based on an imaginary college candidate or job applicant, not on the students we teach in the $\mathrm{K}-12$ classroom." It is obvious that the students are found to be disillusioned and unfit as they are not given adequate training to prepare for higher learning or to enter into the workforce. Tucker (2011, p. 115-116) further explains the present status of unsuccessful students as follows, "The discourse of the dream deferred, rather than inspiring students to prepare for the future, often promotes disillusionment with the present.... The amorphous goal of 'College and Career Readiness' may sound visionary, but it creates a kind of far-sightedness, in the optical sense of the word.... The discourse of the 'dream deferred' distorts our vision of literacy and disheartens the students we actually teach." It can be specifically noted that the students need to be properly trained in terms of language and vocation in schooling itself.

Erling and Walton (2007, p. 38) reported on the use of English language skills in multinational companies in Germany, "The ability to read and understand the essential meaning of English texts was considered to be crucial for employees. ... Another essential skill is the ability to follow and take part in discussions." It is widely considered that fresh employees, irrespective of their position, are expected to communicate in English. The employers, especially, demanded that the new professionals joining the company be fluent in both speaking and writing. They expected them to interact and report in English. In the article "Fit for Work?" (Cheater, 2006), the reflections of the managing director of a London-based international trading company was revealed as, "The quality of French and Japanese work placement students is a lot higher than UK students, not least in the quality of their second language, which is English." The article further sheds light, revealing that the language and social skills of the UK students were found to be very substandard and they were not able to work with the pace of time. The British employers unanimously expected the job seekers to be efficient in displaying academic literacy, social skills, and professionalism. 
In an attempt to propose a job-specific, needs based ESP course, this study investigates the communicative needs of final-year technical students and the demands of HR Managers to develop relevant skills for seeking employment during on-campus recruitments.

\section{Materials and Methods}

\section{Background}

To find out the target demands for developing sufficient employability skills, communicative needs analysis was conducted for final-year Information Technology (IT) students of a technical institution in Tamil Nadu. In the present on-campus recruitment scenario, the technical students failed to successfully communicate in group discussions and personal job interviews. They were not competent enough to convince or negotiate with the recruiters as they faced severe language and communication problems to express themselves clearly in English. Most students lacked effective English communication skills and hence they struggled to organize their thoughts and ideas in English (Sarudin et al., 2009). It was also widely prevalent that most students faced communication apprehension problems like fear, anxiety, and shyness and so they remained reticent and hesitated to actively participate in any oral tasks (Kim, 2006). To understand the target needs of the technical students, needs analysis was conducted with the final-year IT students to help them perform successfully during on-campus interviews. It is considered that industrial and institutional collaboration will be found useful in understanding the perspectives of the employers on their industrial demands (Taillefer, 2007; Lester, 2014; Dickinson \& Griffiths, 2017; Sin \& Amaral, 2017). This research probes to understand that the technical students will be more successful in practicing employability skills with the information sought from the industrial personnel. With the responses of alumni students on their fresh experiences in the software industry, this study focuses on understanding the significance of professional communication and workplace culture.

\section{Participants}

This research was explored on the qualitative ethnographic triangulated perspectives of the finalyear Information Technology (IT) students (38), HR managers (16), and college alumni (7). All of the participating students were 21 years old. The majority of the students ( 33 boys and 5 girls) were all motivated to obtain employment through campus recruitment.
Most of the students were multilingual and few of them hailed from neighbouring states. Some of the students had English as their medium of study. For understanding the real demands of the workplace, HR managers and college alumni working in core industries were the major sources of this research. All the HR managers had more than six years of experience and most of them had technical degrees as their basic qualification. The alumni had a minimum of one year of experience and they were all employed in both Tier I \& II companies. Two English faculty members, along with the present researcher, acted as participant observers in this study.

\section{Materials}

Final-year technical students' learning needs were investigated with a survey based open-ended questionnaire (Please refer to Appendix A). Structured interviews were conducted with the HR managers of the software companies to understand their actual requirements in hiring the candidates (Please refer to Appendix B). Unstructured interviews are conducted with the alumni of the institution to discuss about the real situation in the workplace. In an attempt to gain more insight on the research enquiry, casual interactions and formal discussions with all the participants were undertaken throughout the study.

\section{Research Design}

This research was undertaken with a qualitative ethnographic approach to explore contextual influences through the emic perspectives of the participants (Friberg, 2016). An ethnographic approach can be adopted as a research tool as it helps to understand the subjective and objective reflections of the key players as it depicts the realities of heterogeneous academic and workplace culture. Oanh (2007) compares and contrasts the use of conducting formal and informal needs analysis and considers formal needs analysis to be an effective tool for course design. An informal needs analysis is considered equally important as it facilitates the stakeholders to reflect upon their perceptions and count their experiences in detail. As both formal and informal needs analysis are crucial to observe the job-specific communication needs and demands of the industry, this study specifically intends to elicit more information and working knowledge from both HR managers and working alumni. The survey based open-ended questionnaire was designed to prompt more ideas from the technical students to opine, share, and discuss their needs and expectations while facing job interviews during on-campus recruitment drives. 


\section{Procedure}

The stakeholders of this study were final-year technical students, working alumni, and HR managers. An open-ended needs based questionnaire was administered to the final-year technical students to analyze their employment needs. Their willingness and involvement to share their knowledge and information regarding on-campus recruitments and their expectations for how to be successful in getting into a job market helped the researcher to extend group and pair discussions in both inside and outside classrooms. Casual interactions with the students took place in extra office hours as they remained in the college to attend special coaching classes. Students' contributions in discussions were found to be particularly useful as the open-ended questionnaire met the objectives of the survey to elicit adequate information from them. The alumni were continuously contacted and unstructured interviews were conducted to keep abreast with their professional developments. The final-year technical students were encouraged to communicate with the alumni to create awareness about the prevailing job-related conditions in different workplace environments. The HR managers were contacted directly to conduct structured interviews in their office. As the present researcher considered their insights to be useful in helping the students to prepare for job interviews, all the HR managers affirmed their cooperation and were found to be keenly interested to participate and respond to the interview questions. The purpose of eliciting profound information from the questionnaires and the structured and unstructured interviews was to assess the employment needs of the students while seeking placements during on-campus recruitment events. To acknowledge the original discussions of the stakeholders, their comments were not edited.

\section{Data Analysis}

An ethnography approach to research design was more substantial to gather information of all the HR managers and alumni as their subjective and open-ended statements helped to understand the recruitment process and the prevailing job demands in software companies. The validity of the research can be analyzed through the concept of triangulation - the use of multiple data sources and methods (JassoAguilar, 1999). Questionnaire based surveys and structured interviews were used to conduct a formal needs analysis and the unstructured interviews, casual observations, and discussions were used to conduct an informal needs analysis (Gimenez, 2001; Oanh, 2007). The formal needs analysis was conducted with an open-ended questionnaire to analyze the employment needs of the final-year IT students and the structured interviews were conducted with the HR managers to analyze their target demands in meeting communication requirements to execute jobs effectively. With the alumni, the unstructured interviews were found to be a flexible informal needs analysis research tool to elicit their professional experiences and the challenges they face in the working environment. As both formal and informal needs analysis informs the practicality of the present and target situational context, this research is more benefitted with the observations gained from questionnaire based survey, structured and unstructured interviews.

\section{Results and Discussion}

\section{Conducting a Questionnaire Based Job-Specific Needs Analysis Survey - Final-Year IT Students' Responses}

In response to the first question on the importance of communicating in English, most students had a general awareness about the role of corporate English in global commerce. All the students expressed their willingness to accept that English, being the global language, they need to communicate with it (Huh, 2006). To enter into any industry and sustain their professionalism, they considered communicating in English to be indispensable.

To survive in an industry English is more important, so we need to improve English.

(S. Lakshmi Priya, IV year, IT student)

English is the link language between different countries in the world and hence MNC companies facilitate global communication through English.

(Sharatha Devi, IV year, IT student)

English plays a vital role in today's world. It is a worldwide language; hence it is necessary to learn English. Moreover, it is a professional language so that communicating in English is very important.

(Abirame, IV year, IT student)

All of the students considered the necessity of learning and communicating in English as it is the most instrumental language in commerce and technology. When eliciting a response to the basic skills required for business communication, all of 
the students reported that they consider speaking and writing in English as the most essential skills for business communication.

Speaking and writing is the basement for corporate communication. As without practicing productive skills, communication skills cannot be developed.

(Sneka, IV year, IT student)

It is so important nowadays to get a job. For attending phone interviews and group discussion, speaking skill is very essential. Writing with good language is important for business document preparation.

(Dona Matthew, IV year, IT student)

All of the students responded positively that both speaking and writing skills are the core skills used in every sphere of business and at all levels of professional communication and thus they need sufficient training in it.

In order to understand how speaking and writing skills influence one's opportunity in getting employed, students expected to get trained on how to perform in job interviews. As responding to job-specific interview questions are not specifically practiced, they expected interview skills to be developed to face the recruitment board. While discussing the importance of mock interviews, Kanchana, a IV-year IT student, claimed that the present syllabus is devoid of practical implementations, "Only GDs are conducted. No interviews are there". As interviews are the basic requirement of the placement process, most students expect that it needs to be practically conducted.

In response to preparing students for workplace culture, most of them reflected that they need to get acquainted with the alumni to know more about work shifts, proper attire, and both formal and social communication. As most colleges do not encourage conversations between boys and girls within the campuses, the students are highly motivated by the alumni describing the collaborative working environment between the genders in the workplace. It is asserted that in workplace contexts, irrespective of the gender, all of the employees need to work as a team for the successful completion of a project. Irrespective of gender and time, work shifts are planned to achieve the project goal. In this context, Sukumar, a IV-year IT student, reported,

Some of my expectations are activities like a mock interview and a boy-girl conversation, which is much needed for working in companies.
The students expected that they need to engage in oral presentations and group discussions so they could interact with their peers to exchange information on any topic. It is believed that these task-based activities will help them to participate and perform better in teamwork in a future workplace.

While discussing the improvements that can be done in career education and placement training, most students confessed that merely understanding important tips for interview questions is not sufficient. They wish that they had the opportunity to practically perform mock interviews in the practical sessions. Balaji, a IV-year IT student, remarked, "To seek better jobs, productive skills are necessary". As the effect of schooling can be found in shaping their communicative ability, the institution needs to be more responsible for engaging the students to perform relevant job-specific tasks to face workplace requirements. Shalini, a IVyear IT student, reflected that the present academic syllabus needs to be updated with the specification of skills related to workplace contexts,

The present syllabus is based on theoretical knowledge and not a practical one. It must be transformed as a practical session having mock interviews, face-to-face chatting, and presentations with maximum minutes.

D. Ramya, a IV-year IT student, argued that the allocation of time for oral presentations and group discussions should be increased. Aarthy, a IV-year IT student, revealed that more practical sessions in communication are needed and special teaching on technical writing, project guidance, and mock interviews will be helpful for their future career. All of the students expected ample guidance on understanding the expectations of their future employers.

\section{Conducting Unstructured Interviews - Alumni Responses}

All of the alumni specifically reported that the students need to be given sufficient insight into understanding the requirements of the workplace as fresh professionals should be capable of interacting via both teleconferencing and video conferencing, sending and receiving emails, and reporting their progress on their projects (Nickerson, 2005). They consistently emphasized the need to be able to sell ideas to other people, convince the colleagues and team leaders, and hold the listener's attention when they speak. Most of the alumni also stressed the need for writing professional emails and technical reports.

Fresh employees are placed to work 
collaboratively in a team. They need to communicate with their colleagues and team leaders. They need to closely work with their associates to understand about their project. They need to discuss and report their progress in their job.

(Iliyas Ahmed, Alumnus)

As professionals are often sending and receiving emails, they need to be brief and precise in reporting their job related information. They need to be very focussed with their job and should be very clear and concise while attending and answering calls.

(Ananya Suraj, Alumnus)

Most of the alumni reflected that as employees need to interact with international clients, they should be aware of both UK/US pronunciation and accent variations. They should be familiar with the differences found in the international accents of English. In this context, most of the alumni stressed the importance of both UK and US accents, as they are preferred by the respective UK and US-based multinational companies. Even in the interview rounds, students are tested for speaking as well as understanding the international accents. While discussing the importance of international accents, V. Keerthana Selvam, an alumnus, revealed, "Most companies expect the students to speak and understand US accents. They are specifically tested for communicating with US clients". $\mathrm{S}$. Ram Kumar, an alumnus, reported on the testing of international accents, "Communication skills are tested. US accents on audio recordings will be played and the emerging professionals will be tested on them". When discussing the students' deficiencies in oral and written communication, all of the alumni insisted that the students need to be given sufficient training on the mechanisms of both speaking and writing. While pronunciation problems are encountered while speaking, spelling mistakes are widely seen in writing. Committing spelling errors has become a worldwide issue indistinct to both native and non-native users of English. Hence, all of the alumni put a great deal of emphasis on developing error-free writing skills, particularly in business emails and reports.

\section{Conducting Structured Interviews - HR Managers' Responses}

In the structured interviews, all of the HR managers specifically mentioned that new engineering professionals lack both oral and written communication skills (Ehrich et al., 2010). Some believe that their oral communication is better than their writing ability and others reported that they are able to write better than they speak. As their language skills are found to be not satisfactory, a large decrease in English language ability has been seen over the last decade. It is a common expectation that job seekers need to have excellent English communication skills. When discussing the vital role of communication skills in job interviews, Goutham, an HR executive of Sellasynergy India Ltd., revealed, "Both speaking and writing skills are important. Verbal, non-verbal, and personality elements tag with one another. As a whole, verbal and nonverbal communication skills build the personality of an individual". Further, in this context, Rajaraman. R, an HR manager of First Source Solution Ltd., also stressed,
Communicating in English is very important. Grammar is necessary. Listening is pivotal.If a client is an international client, communication is to be done in English only; otherwise it is in terms generally bilingual. Customers should understand their language. Literally, professionals are lacking in productive skills and particularly in writing.

Most of the prospective and emerging professionals are aware that language and communication skills are the basic requirement to seek a better position (Eraut, 2004). As most students fail to communicate effectively in English and also lack adequate communication skills, they are unsuitable for the prevalent on-campus job opportunities, thus leading to unemployment. All of the HR managers reported that English has become the basic requirement when hiring a candidate. As top level managers and service personnel need to interact with international clients in English, the HR managers specifically emphasized that prospective employees need to develop presentation skills to discuss, persuade, convince, and negotiate in English.
Managerial-level meetings will be only in English. When the candidates are put with the foreigners, they are not able to cope up with the situation to speak in English. They need to be better trained to develop presentation skills in English. (Mani. S, HR manager, Vee Technologies Ltd.)

All of the HR managers were found to be generally concerned with the objectives of the curriculum as they often discovered the relevant knowledge and skills were not transferred from academic to workplace contexts. They expected that the learning of employability skills should be practically found in their degree programmes. As work-based learning was 
not covered in the curriculum, students were unable to meet the requirements of the employers. They opined that a communications department should be established to provide constant awareness and training on developing necessary skills to transfer from academic to workplace contexts. HR managers reflected that the level of communication they expect from the professionals was generally lacking in the educational market today. They should know the right way to speak and how to speak with colleagues and subordinates. They should be able to communicate in English and keep rapport with everyone from the top cadre to the bottom-level employees. HR managers stated that new professionals lack adequate knowledge and information on current affairs. As they lack sufficient information, they were found to be devoid of good communication skills. They are unable to confidently participate and engage in both professional and casual interactions. They were not adequately prepared with their technical knowledge and they lacked practical communication skills. In this context, Goutham, an HR Executive of Sellasynergy India Ltd., reported that students are oriented towards their technical subjects and general awareness and knowledge of current affairs is missing.

Regarding the contributions of university education in helping the students more employable, most of the HR managers revealed that the university curriculum is more theory based and so the engineering graduates are specifically lacking practical knowledge in their subject. As the students are not able to interpret and discuss the technical content, all of the HR managers anticipate their practical working knowledge on those theories. It is their contention that the technical subjects are taught with more theoretical underpinnings and hence they expect employees with more practical knowledge than on their theoretical expertise. All of the HR managers unanimously agreed that the areas of immediate concern are the students learning discrepancies in acquiring sufficient technical knowledge, language fluency, and strategic skills. These learning discrepancies need to be specifically addressed in university education. They reported that in the academic studies, presentation skills and interpersonal and group communication skills are seldom encouraged. They stressed that the curriculum should be application oriented to meet their workplace needs. Vinod, an HR manager of Kumaran Systems, revealed, "The present university educational system should stress more on business communication. Language skills could be taught practically in a business context. For example how to draft mails, documents, etc. should be necessarily practiced by the students". It is explicitly emphasized that language and communication skills should be practiced through writing business letters, emails, and reports. Further, all of the HR managers considered that oral presentations, group discussions, and mock interviews as well as writing business letters, emails, and reports need to be practiced rather than just giving guidelines in the classes.

In response to the role and significance of verbal and nonverbal skills in professional communication, all of the HR managers considered developing speaking and writing skills as the core verbal skills as they are crucial for communicating in both oral and written business transactions. The companies strive to organize team work and create professional networks to undertake projects effectively. They revealed that the internal and external communication of any organization is solely possible only through the skills of speaking and writing (Cowling, 2007). Goutham, an HR Executive of Sellasynergy India Ltd., stressed, "Soft skills on par with verbal skills can be assigned to develop better communication skills. Neatness and perfectness is the hallmark of one's personality and it displays one's disciplined behaviour and positive attitudes". In the unstructured interviews, many alumni reported that their companies consider verbal and nonverbal skills equally important when distinguishing the positive and negative traits of the individual.

In order to determine how the students can shape themselves to become a more attractive prospective employee, the HR managers revealed that professionals need to understand where they should be brief and objective in their tone and thoughts and when they should describe and explain in more detail on any subject. They anticipated that their employees would know how to interact in both formal and social contexts, and disapprove of unnecessary and superfluous communication. They recommended that students improve their soft skills and managerial skills for developing a strong and optimistic personality. In this context, Anitha Nancy, an HR executive (Training) of Thales Software India Pvt. Ltd., revealed, "Interpersonal, negotiation, and convincing skills are important. Building team spirit and time management are essential among the workforce. To develop soft skills is to develop personality". Further, Ambikapathi, an HR manager of Precision Equipments Pvt. Ltd., also reported,

Soft skills are absolutely needed to perform in better way. Most of the freshers are afraid to speak in English. They should be self-confident. We provide training on technical, communication skills and soft skills to our employees. Self-exaggeration in speech is not good. Honesty pays for a better personality.

Most of the HR managers believed that analytical 
thinking and aptitude skills need to be improved. Marketing skills, customer relationship skills, convincing and negotiating skills are necessary to develop interaction and strategic skills. They expected thatjobseekersneed tobeself-confidentand self-reliant in executing their business tasks. For improving the students' business etiquette, soft skills are considered the most wanted skills, on par with communication and technical knowledge. Hence, technical, verbal, and soft skills are considered the three-tiered skills for augmenting employability. Admitting the credentials of soft skills over productive skills, Dr. Padmavathy Srinivasan, CEO, Winspire Language World, reflected, "Soft skills are more important than productive skills. Soft skills can get you what you want. It credits the character and personality. They need to know when to soft/hard peddle in the business situation".

In response to the measures that academies can take to provide career education and placement training to the students, K.S. Balaji, Project Engineer, Wipro Technologies, reflected that the process of teaching and learning of content and skills should be done on par with the training of the requirements of the companies. The HR managers were generally concerned about developing teachers' competencies to teach and communicate in English with the students. All of the HR managers considered the importance of providing job-specific training to the employees. Santhosh Raj, an alumnus, reflected that almost all companies provide pre-service and in-service training to their employees for the smooth progress and functioning of their projects. As the employees are often lacking sufficient technical and business acumen, they generally consider providing job-related training pertained to their area of job-specific domains to be essential.

Most of the HR managers stressed that prospective employees should be able to draft documents for written correspondences (Louhiala-Salminen et al., 2005). Their writing skills need to be developed to globalize business transactions. Their interpretations through both verbal and graphical modes need to be strongly practiced as they should be able to display their technical knowledge through interactive and visual communication. This will help them transfer their knowledge and skills in undertaking technical and business projects (Forey, 2004; Dovey, 2006). As all of their speaking and writing skills relevant to business communication were often found to be neglected in the university curriculum, this should be updated (Dolton \& Vignoles, 2002). The revised syllabus needs to satisfy the students' job-specific needs as they should emerge prepared to meet the professional demands of the workplace.

In response to promote campus placements, all of the HR mangers claimed that education and training should be synergized effectively. They commonly shared that if the university syllabus matches with the trends of professionalism required in the present job market, the students will get sufficient awareness and time to understand and practice the required skills meant for their employment. As high school has the biggest impact on students, communication and soft skills need to be integrated in the academic curriculum. If the syllabus matches with careeroriented objectives and adequate teaching and training is provided, engineering students will be more prepared to face the job market (Basturkmen, 2012; Edwards, 2014). If the technical subjects are taught through communicative activities such as group discussion and seminars, students will be able to reduce their communication apprehension. As new professionals need to interact with onshore and overseas clients, they need to confidently present and discuss their ideas. The students need to develop both critical and emotional intelligence to work in any business environment. Emerging professionals need to transfer their educational insights into professional pursuits as the transition from academic environment to the workplace cannot be ignored (Andrews \& Russell, 2012; Donald et al., 2018).

\section{Suggestions for Designing a Needs Based ESP Course}

Analyzing the communicative needs of the finalyear IT students, the perceptions of the alumni and the demands of the HR managers, it is proposed that the following factors need to be considered when designing a syllabus for a needs based ESP course for seeking placements.

1. A job-specific, needs based communicative syllabus should be devised.

2. Implementing, revising, and incorporating necessary changes in the syllabus to the needs of both academics and industry should be performed continuously.

3. Eclectic and pragmatic approaches should be practiced.

4. Appropriate teaching methodologies and techniques need to be followed in language pedagogy.

5. Students need to participate and perform jobspecific communicative tasks.

6. Practicing speaking skills through individual oral presentations as well as dyadic and group communication activities should be made compulsory.

7. Reading newspapers, watching English 
documentaries, and using Internet resources should be practiced.

8. Teachers should identify the communicative level of the students and should provide consistent feedback on the tasks.

9. With the concurrence of the teacher, students need to select relevant themes and topics for language learning.

10. Teachers need to prepare necessary worksheets, handouts, and other supplementary materials for teaching and practicing LSRW skills.

11. Authentic work-based resources should be used for language learning.

12. Mechanics of speaking and writing should be practiced.

13. Adequate practice of business writing skills should be compulsory.

14. Students need to be encouraged to be more dynamic and assertive in their behaviour.

15. The teaching and testing of speaking should be done through speaking only.

16. Testing and evaluation should be done genuinely by examining the real performance of the students.

17. Adequate training should be given to both teachers and students to enrich interaction skills.

18. Employability skills need to be constantly practiced for proving job effectiveness in their work.

All of the HR personnel expected the technical students to develop relevant employability skills. As they regularly observed the grammar, vocabulary, and spelling mistakes that are often found in writing, they encouraged students to practice basic language skills. They also expected the students to be provided sufficient training on the role of corporate culture (Ahiauzu, 1984). They should be given sufficient awareness on the necessity to manage time and stress when discharging their duties. They need to be constantly reminded on their urgency to achieve their target goals. They need to be more pragmatic to update their general and technical knowledge and job-domain skills. It is expected that the technical students' aspirations must balance with their capability, knowledge, and skills (Tymon, 2013; Lester, 2014; McCowan, 2015; Clokie \& Fourie, 2016). As their personal and professional development is based on knowledge, ability, language, and communication and management skills, they need to prove themselves through their stability and integrity in action.

\section{Conclusion}

This study discusses the personal and professional needs of final-year IT students. The perceptions of HR managers were observed to analyze the employment demands of the industry. All of the HR managers unanimously considered the role of both verbal and nonverbal skills for expressing one's views in business, technical, and social interactions to be vital. They agreed that it has become crucial on the part of professionals to execute their job with relevant discursive, social, and technical skills. This research reflects on developing students' knowledge, skills, and attitudes that could cater to the needs of the working environment. With the findings of the research, it can be implied:

- Academic and professional awareness of workplace can be sought while discussing the job and company profile. Further, engineering students can be encouraged to undertake industrial visits along with faculty members for gaining sufficient exposure to workplace culture.

- Alumni meetings can be officially conducted once in a semester, where they can share their professional experiences on their technical progress, promotions, and the frequent shifting of jobs. This will help the students better understand the company' top priorities and job functions.

- Information regarding job prospects, recruitment ideologies and the effect of globalization on the economy and commerce can be gathered through both HR managers and alumni.

Assessing the language needs of students both in the context of the present and target situations will help syllabus experts to design a specific needs based ESP course (Fatihi, 2003). This study implies the positive development of institutional and industrial collaboration in meeting the purpose of the jobspecific, needs based courses. It was found that offering suggestions, instructions, directions, and recommendations facilitate corporate dynamics. Team building and leadership qualities are emphasized to develop managerial skills. Understanding the workforce, building rapport, and team support are some of the significant interpersonal elements that any business management is connected with. Emerging professionals need to be acquainted with these traits and should possess sufficient knowledge and the capability to work collaboratively. As English language ability and communicative competence are 
vital in both academia and industry, this research recommends developing verbal, nonverbal, and management skills to successfully communicate in target situations.

\section{References}

Ahiauzu, A. (1984). Cross-cultural study of job regulation at the workplace: A framework for analysis. Indian Journal of Industrial Relations, 19(3), 295-329.

Andrews, G., \& Russell, M. (2012). Employability skills development: Strategy, evaluation and impact. Higher Education, Skills and Work-Based Learning, 2(1), 33-44. doi:10.1108/20423891211197721

Basturkmen, H. (2012). Languages for specific purposes: Curriculum creation and implementation in Australasia and Europe. The Modern Language Journal, 96, 59-70. doi:10.1111/j.15404781.2012.01297.x

Belcher, D. D. (2006). English for specific purposes: Teaching to perceived needs and imagined futures in worlds of work, study, and everyday life. TESOL Quarterly, 40(1), 133-156. doi:10.2307/40264514

Berwick, R. (1989). Needs assessment in language programming: From theory to practice. In R. Johnson (Ed.), The Second Language Curriculum (pp. 48-62). Cambridge, UK: Cambridge University Press.

Cheater, A. (2006). Focus: Fit for work? English Today, 22(1), 51-53. doi:10.1017/S0266078406001088

Choudhury, T. A. (2009). Identifying the English language needs of Humanities students at Dhaka university. The Dhaka University Journal of Linguistics, 2(4), 59-92.

Clokie, T. L., \& Fourie, E. (2016). Graduate employability and communication competence: Are undergraduates taught relevant skills? Business and Professional Communication Quarterly, 79(4), 442-463. doi: $10.1177 / 2329490616657635$

Cowling, J. D. (2007). Needs analysis: Planning a syllabus for a series of intensive workplace courses at a leading Japanese company. English for Specific Purposes, 26(1), 426-442. doi:10.1016/j. esp.2006.10.003

Crosling, G., \& Ward, I. (2002). Oral communication: The workplace needs and uses of business graduate employees. English for Specific Purposes, 21(1), 4157. doi:10.1016/S0889-4906(00)00031-4

Davies, C., \& Birbili, M. (2000).What do people need to know about writing in order to write in their jobs? British Journal of Educational Studies, 48(4), 429445. doi:10.1111/1467-8527.00156

Dickinson, J., \& Griffiths, T. L. (2017). Building bridges: A critical analysis of university-industry collaboration to improve diverse access to elite professions. Industry and Higher Education, 31(4), 227-238. doi:10.1177/0950422217707641

Dolton, P. J., \& Vignoles, A. (2002). Is a broader curriculum better? Economics of Education Review, 21(1), 415-429. doi:10.1016/S0272-7757(01)000462

Donald, W. E., Ashleigh, M. J., Baruch, Y. (2018). Students' perceptions of education and employability: Facilitating career transition from higher education into the labor market. Career Development International, 23(5), 13-540. doi: 10.1108/CDI-09-2017-0171

Dovey, T. (2006). What purposes, specifically? Rethinking purposes and specificity in the context of the 'new vocationalism'. English for SpecificPurposes, 25(4), 387-402. doi:10.1016/j.esp.2005.10.002

Edwards, M. (2014). The impact of placements on students' self-efficacy. Higher Education, Skills and Work-based Learning, 4(3), 228-241. doi:10.1108/ HESWBL-05-2014-0015

Ehrich, J. F., Kim, S. H. O., \& Ficorilli, L. (2010). Competency based assessment, employment and immigrant background: An exploratory investigation of adult language learners in Australia. Language and Education, 24(6), 485-494. doi:10.1080/09500782.2010.499173

Eraut, M. (2004). Transfer of knowledge between education and workplace settings. In H. Rainbird, A. Fuller \& A. Munro (Eds.), Workplace Learning in Context (pp. 201-221). London \& NY, NY: Routledge.

Erling, E., \& Walton, A. (2007). English at work in Berlin. English Today, 23(1), 32-40. doi:10.1017/ S026607840700106X

Fatihi, A. R. (2003). The role of needs analysis in ESL program design. South Asian Language Review, 13(1\&2), 39-59.

Forey, G. (2004). Workplace texts: Do they mean the same for teachers and business people. English for Specific Purposes, 23(1), 447-469. doi:10.1016/j. esp.2004.01.003

Friberg, T. (2016). Generating ethnographic research questions: An anthropological contribution to the study of higher education. Ethnography and Education, 11(3), 345-358. doi: 10.1080/17457823.2015.1101386

Gimenez, J. C. (2001). Ethnographic observations in cross-cultural business negotiations between nonnative speakers of English: An exploratory study. English for Specific Purposes, 20(2), 169-193. doi: 10.1016/S0889-4906(99)00038-1

Gray, F. E., Emerson, L., \& MacKay, B. (2005). Meeting the demands of the workplace: Science students and written skills. Journal of Science Education and Technology, 14(4), 425-435. doi: 10.1007/s10956- 
005-8087-y

Huh, S. (2006). A task-based needs analysis for a business English course. Second Language Studies, 24(2), 1-64.

Hutchinson, T., \& Waters, A. (1987). English for specific purposes: A learning centred approach. Cambridge, UK: Cambridge University Press.

Jasso-Aguilar, R. (1999). Source, methods and triangulation in needs analysis: A critical perspective in the case study of Waikiki Hotel maids. English for Specific Purposes, 18(1), 27-46. doi:10.1016/S0889-4906(97)00048-3

Kassim, H., \& Ali, F. (2010). English communicative events and skills needed at the workplace: Feedback from the industry. English for Specific Purposes, 29(3), 168-182. doi:10.1016/j.esp.2009.10.002

Kayi, H. (2008). Developing an ESL curriculum based on needs and situation analyses: A case study. Journal of Language and Linguistic Studies, 4(1), 29-49.

Kim, S. (2006). Academic oral communication needs of East Asian international graduate students in non-science and non-engineering fields. English for Specific Purposes, 25(1), 479-489. doi:10.1016/j. esp.2005.10.001

Lester, S. (2014). Professional standards, competence and capability. Higher Education, Skills and Work-based Learning, 4(1), 31-43. doi:10.1108/ HESWBL-04-2013-0005

Long, M. H. (2005). Methodological issues in learner needs analysis. In M. H. Long (Ed.), Second Language Needs Analysis (pp. 19-76). Cambridge, UK: Cambridge University Press.

Louhiala-Salminen, L., Charles, M., \& Kankaanranta, A. (2005). English as a lingua franca in Nordic corporate mergers: Two case companies. English for Specific Purposes, 24(4), 401-421. doi:10.1016/j. esp.2005.02.003

McCowan, T. (2015). Should universities promote employability? Theory and Research in Education, 13(3), 267-285. doi:10.1177/1477878515598060

Nickerson, C. (2005). English as a lingua franca in international business contexts. English for Specific Purposes, 24(1), 367-380. doi:10.1016/i. esp.2005.02.001

Nunan, D. (1996). Syllabus Design. Oxford, UK: Oxford University Press.

Oanh, D. T. H. (2007). Meeting students' needs in two
EAP programmes in Vietnam and New Zealand: A comparative study, RELC Journal, 38(3), 324-349. doi: $10.1177 / 0033688207085850$

Pavlin, S., \& Svetlik, I. (2014). Employability of higher education graduates in Europe. International Journal of Manpower, 35(4), 418-424. doi:10.1108/ IJM-05-2013-0104

Rogerson-Revell, P. (2007). Using English for international business: A European case study. English for Specific Purposes, 26, 103-120. doi:10.1016/j.esp.2005.12.004

Rhoder, C. A., \& French, J. N. (1994). Workplace literacy: From survival to empowerment and human development. Journal of Reading, 38(2), 110120.

Sarudin, I. H., Zubairi, A. M., \& Ali, A. M. (2009). A comparative analysis of engineering students' problems in speaking and writing. In Proceedings of the $2^{\text {nd }}$ International Conference of Teaching and Learning (ICTL), INTI University College, Malaysia. Retrieved from ictl.intimal.edu.my/ ictl2009/.../5C/5C-01-P170\%20(Malaysia).doc

Sin, C., \& Amaral, A. (2017). Academics' and employers' perceptions about responsibilities for employability and their initiatives towards its development. Higher Education, 73(1), 97-111. doi: 10.1007/s10734-016-0007-y

Spence, P., \& Liu, G. (2013). Engineering English and the high-tech industry: A case study of an English needs analysis of process integration engineers at a semiconductor manufacturing company in Taiwan. English for Specific Purposes, 32(2), 97-109. doi: 10.1016/i.esp.2012.11.003

Taillefer, G. F. (2007). The professional language needs of Economics graduates: Assessment and perspectives in the French context. English for Specific Purposes, 26, 135-155. doi:10.1016/i. esp.2006.06.003

Tucker, B. (2011). The dream deferred: How "College and Career Readiness" looks from below. English Journal, 100(3), 115-116.

Tymon, A. (2013). The student perspective on employability. Studies in Higher Education, 38(6), 841-856, doi:10.1080/03075079.2011.604408

West, R. (1994). Needs analysis in language teaching. Language Teaching, 27(1), 1-19. doi:10.1017/ $\underline{\text { S0261444800007527 }}$ 


\section{Appendix A}

Needs analysis on employability skills for placement

Open ended questionnaire for analyzing the employment needs of the final-year IT students

Name of the Student:

Name of the Institution:

Branch \& Year:

Date:

1. Why do you consider communicating in English to be important?

2. What are the basic skills for business communication?

3. How far do speaking and writing skills influence one's opportunity in getting a placement? How can they be developed?

4. How can the students develop workplace culture in academia?

5. How can the students be successful in getting placements in their course of study?

\section{Appendix B}

Needs analysis on employability skills for placement Open-ended questionnaire for conducting structured interviews with the HR Managers

Name of the Professional:

Designation:

Name of the Organization (with address):

Educational Qualification:

Professional Experience:

1. How much are English communication skills considered to be an important requirement for employability? Why?

2. How much has university education succeeded in helping students become more employable?

3. What is the role of verbal and nonverbal skills in professional communication?

4. How can students shape themselves to become more attractive to a prospective employee?

5. How can academies provide career education and placement training to students? 